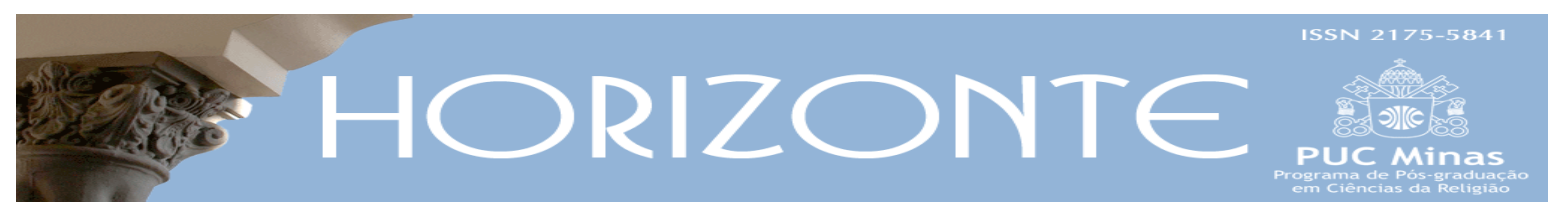

Dossiê: Religião, Direitos Humanos e Direitos da Natureza - Artigo Original ๑。으.

\title{
Igreja Católica, direitos reprodutivos e direitos ambientais
}

\author{
Catholic Church, reproductive rights and environmental rights
}

\author{
José Eustáquio Diniz Alves* \\ Suzana Cavenaghi**
}

\begin{abstract}
Resumo
O objetivo deste texto é apresentar e debater alguns pontos de interseção da esfera dos direitos humanos com o campo da religião, abordando, em especial, os encontros e desencontros referentes às doutrinas da Igreja Católica sobre os direitos reprodutivos e os direitos ambientais. Para tanto, reconstituímos uma narrativa histórica e relacional do debate sobre as origens e a evolução da transição demográfica e dos direitos humanos, desde a época da Revolução Francesa. Por meio de uma análise comparativa e contextualizada, apresentamos o debate sobre população e desenvolvimento sustentável e as visões sobre os direitos reprodutivos e ambientais expostos em Conferências da Organização das Nações Unidas e nas encíclicas Humanae Vitae e Laudato Si'. Argumentamos que desde o final do século XVIII até os dias atuais, o progresso humano se deu às custas do regresso ambiental. Como sociedade e ambiente estão percorrendo rotas opostas, a necessidade de reconstituição da biocapacidade do Planeta requer uma reflexão sobre a dinâmica do crescimento demoeconômico e a efetivação dos direitos reprodutivos e ambientais. Desta forma, assinalamos que no Estado democrático de direito, com respeito aos princípios da laicidade, a tolerância religiosa é essencial para o adequado equacionamento da questão dos direitos reprodutivos e para o aprofundamento do debate sobre os direitos ambientais.
\end{abstract}

Palavras-chave: Religião. Igreja Católica. Direitos Reprodutivos. Direitos Ambientais.

\begin{abstract}
The purpose of this paper is to present and discuss some points of intersection of the human rights realm with the field of religion, addressing in particular the agreements and disagreements regarding the doctrines of the Catholic Church on reproductive rights and environmental rights. To that end, we reconstruct a historical and relational narrative of the debate about the origins and evolution of the demographic transition and of human rights, since the time of the French Revolution. By means of a comparative and contextualized analysis, we portray about the debate on population and sustainable development and the views on reproductive and environmental rights set forth in United Nations International Conferences and in the encyclicals Humanae Vitae and Laudato $\mathrm{Si}$ '. As society and the environment are going through on opposite routes, the need to reconstitute the planet's biocapacity requires a reflection on the dynamics of demoeconomic growth and the achievement of reproductive and environmental rights. Accordingly, we point out that in the democratic State of law, with respect to the principles of secularity, religious tolerance is essential for the adequate consideration of reproductive rights issues and for deepening the debate on environmental rights.
\end{abstract}

Palavras-chave: Religion. Catholic Church. Reproductive Rights. Environmental Rights.

Artigo submetido em 31 de julho de 2017 e aprovado em 27 de setembro de 2017.

*Doutor em Demografia (CEDEPLAR/UFMG), pós-doutorado (NEPO/ Unicamp), professor titular do PPG em População, Território e Estatísticas Públicas da Escola Nacional de Ciências Estatísticas (ENCE/IBGE). País de Origem: Brasil. E-mail: jed_alves@yahoo.com.br

** Doutora em Demografia (The University of Texas at Austin), professora do PPG em População, Território e Estatísticas Públicas da Escola Nacional de Ciências Estatísticas (ENCE/IBGE). País de Origem: Brasil. E-mail: suzana_cavenaghi@uol.com.br

Horizonte, Belo Horizonte, v. 15, n. 47, p. 736-769, jul./set. 2017 - ISSN 2175-5841 


\section{Introdução}

As reconfigurações das instituições próprias da modernidade, juntamente com o concurso da racionalização e da materialidade do sistema produtivo, redefiniram o papel da religião na organização da sociedade, possibilitando, na concepção weberiana, um complexo processo de "desencantamento do mundo" (PIERUCCI, 2003). A Revolução Francesa foi um dos marcos fundamentais da modernidade, pois possibilitou a separação entre Igreja e Estado (SABORIT, 2009) e também viabilizou uma "inversão histórica" ao definir uma ordem constitucional onde "passou-se da prioridade dos deveres do súdito à prioridade dos direitos dos cidadãos" (BOBBIO, 1992, p. 3).

Sem dúvida, religião e direitos humanos estiveram no centro da dinâmica dos acontecimentos da Revolução Francesa. Por um lado, em decorrência do sentimento anticlerical dos iluministas, os revolucionários tomaram várias medidas contra os privilégios da Igreja Católica, tais como a supressão do dizimo, o confisco dos bens do clero para saldar o déficit nacional e a retirada do status de "poder divino" do rei Luís XVI. Por outro lado, pouco mais de um mês após a queda da Bastilha, em 1789, a Assembleia Nacional aprovou a Declaração dos Direitos do Homem e do Cidadão, definindo os direitos individuais como sendo naturais e universais.

Todavia, os direitos de cidadania iriam demandar diversas etapas para se desenvolver. De acordo com T. H. Marshall (1967), a evolução dos direitos humanos se deu em três gerações: civil, política e social. Com base na experiência inglesa, Marshall relacionou os direitos civis (Habeas Corpus, abolição da censura à imprensa, direito consuetudinário, etc.) ao século XVIII, os direitos políticos (direito ao voto, direito de associação, etc.) ao século XIX e os direitos sociais (legislação trabalhista e previdenciária, educação, saúde, etc.) ao século XX. 
Em sua evolução histórica, a universalização dos direitos teve um ponto de inflexão em 1948, quando a Organização das Nações Unidas (ONU), no bojo de uma reconfiguração da ordem internacional do Pós-Guerra, aprovou a Declaração Universal dos Direitos Humanos, introduzindo a concepção contemporânea de universalidade e indivisibilidade destes direitos e a ideia de que a simples condição de pessoa tornou-se o atributo único e exclusivo para a titularidade dos direitos humanos, sendo proibida qualquer discriminação ou distinção de raça, de cor, de sexo, de língua, de religião, de opinião política ou outra, de origem nacional ou social, de fortuna, de nascimento ou de qualquer outra situação.

No processo de implementação da Declaração Universal, a Assembleia Geral da ONU, por unanimidade, aprovou em 10 de dezembro de 1968, o Pacto Internacional de Direitos Civis e Políticos e o Pacto Internacional de Direitos Econômicos, Sociais e Culturais. Contudo, foi somente em 1993, quando ocorreu a segunda Conferência Mundial de Direitos Humanos, em Viena, realizada após o fim da Guerra Fria, que se avançou no sentido da indivisibilidade dos direitos civis, políticos, econômicos, sociais e culturais.

Em 2018, a Declaração Universal dos Direitos Humanos completará setenta anos, devendo ser comemoradas as conquistas realizadas nesse período, mas também sendo uma oportunidade para se refletir sobre as lacunas ainda existentes e como garantir a integração entre os direitos humanos e os direitos ambientais.

\section{População, religião e reprodução humana}

A questão da reprodução é parte central da história humana. Desde o surgimento do Homo Sapiens, há duzentos mil anos, a humanidade travou uma batalha diária pela sobrevivência e pela superação das altas taxas de mortalidade. Para tanto, as sociedades, pelo menos aquelas que conseguiram prosperar, se organizavam para garantir que os nascimentos superassem os óbitos. A cultura, em geral, e a religião, em particular, se incumbiram da tarefa de evitar a depopulação e garantir, mesmo que em ritmo lento, o contínuo crescimento populacional. 
Segundo o American Museum of Natural History (2016), a população humana estava em torno de 5 milhões de habitantes por volta de 10 mil anos atrás, chegou a 170 milhões no ano 1 da era cristã, atingiu cerca de 450 milhões de pessoas na época do descobrimento da América e alcançou 1 bilhão de habitantes, por volta de 180o, no início da Revolução Industrial e Energética, quando o uso de combustíveis fósseis e a utilização de maquinaria possibilitou um grande domínio da economia sobre a natureza e um aumento exponencial do número de habitantes do globo, que se encontra na casa de 7,5 bilhões de pessoas em 2017.

O rápido crescimento da população após o início da Revolução Industrial foi acompanhado por um crescimento ainda mais rápido da economia, o que, a despeito das desigualdades, possibilitou a melhoria do padrão médio de vida e a ampliação dos direitos humanos nas áreas de saúde, educação, moradia, alimentação, lazer, etc. Mas o progresso humano se deu de forma desigual e às custas do regresso ambiental. Como nos ensinaram os mestres da Economia Ecológica (BOULDING, 1966; DALY, 1968), é impossível manter um crescimento infinito em um Planeta finito. $\mathrm{O}$ crescimento exponencial das atividades antrópicas (todas as ações humanas), no modelo atual, é inviável no longo prazo, sendo que a população e a economia precisam compartilhar o mesmo e único meio ambiente terrestre com as demais espécies da comunidade biótica. Portanto, direitos humanos (incluso direitos reprodutivos) e direitos ambientais são complementares e indivisíveis.

Contudo, o crescimento populacional mundial dos dois últimos séculos tem, historicamente, ocorrido de forma conflituosa, muitas vezes desconsiderando os direitos reprodutivos. Desde a segunda metade do século XVIII, o chamado "problema populacional", em suas diversas dimensões, não passou desapercebido aos iluministas e defensores da Revolução Francesa. Escrevendo no início dos anos de 1790, o Marquês de Condorcet, na França, e William Godwin, na Inglaterra, foram pensadores e revolucionários que compreenderam que o progresso humano estava condicionado à redução das taxas de mortalidade e ao aumento da esperança de vida. Porém, para haver sustentabilidade demográfica, os ganhos de 
sobrevida requeriam um ajuste das altas taxas de fecundidade. Como mostrou Alves (2002), Condorcet e Godwin podem ser considerados precursores da demografia, pois, de forma teórica e intuitiva, mas de maneira presciente, previram o fenômeno da transição demográfica (passagem de altas para baixas taxas de mortalidade e natalidade).

Mas quem ganhou fama nesta área foi o economista inglês Thomas Malthus que, em 1798, publicou um panfleto anônimo denominado "Ensaio sobre o princípio de população e seus efeitos sobre o aperfeiçoamento futuro da sociedade, com observações sobre as especulações de Mr. Godwin, Mr. Condorcet e outros autores”. Malthus era um crítico contundente da Revolução Francesa e apresentou uma visão oposta aos pensadores iluministas. Contrariamente ao que viria acontecer com o fenômeno da transição demográfica, Malthus formulou um princípio de população que dizia o seguinte: “(...) a população, quando não controlada, cresce numa progressão geométrica, e os meios de subsistência numa progressão aritmética” (MALTHUS, 1983, p.283).

Para resolver o "problema populacional, no princípio malthusiano, o controle da população viria do aumento das taxas de mortalidade, em decorrência dos vícios, doenças e guerras, fenômenos que ele chamava de “freios positivos". É importante destacar que neste princípio Malthus defende o controle pelo lado da mortalidade e não de um controle da natalidade. Esta postura decorre do fato que, como pastor da Igreja Anglicana, ele tinha posicionamento contrário aos meios artificiais de controle da natalidade, contra a esterilização e contra o aborto. Apenas na segunda versão do "Ensaio", Malthus introduziu o conceito de "freio preventivo", referindo-se ao adiamento da idade ao casar, como uma forma de controle da natalidade. De acordo com a doutrina de sua igreja, ele pregava a ideia de abstinência sexual antes do matrimônio, mas o sexo com finalidade procriativa depois das núpcias. O casamento tardio diminuiria o tempo de exposição à gravidez e reduziria a taxa de natalidade, mesmo sem a utilização de métodos contraceptivos. 
Malthus era um ideólogo conservador e um porta-voz dos interesses dos grandes proprietários de terra, da nobreza e do clero. Ele se opunha às propostas da burguesia nascente e ao progresso das classes trabalhadoras. Assim, como forma de controle da população ele defendia um salário de subsistência ao mesmo tempo que garantia a renda da terra das elites rurais. Seguindo esta linha, ele foi contra a liberação do comércio e a importação de cereais, como reivindicavam os setores urbanos da Inglaterra de seu tempo. Também foi contra a "lei dos pobres", que eram ações beneficentes visando aliviar situações de pobreza extrema. Desta forma, não somente não pregava os direitos reprodutivos como tampouco os direitos humanos, já defendidos à época por muitos (ALVES, 2002).

Evidentemente, o pensamento de Thomas Malthus foi bastante criticado pelos defensores da classe operária que lutavam contra a superexploração do trabalho e os baixos salários. As forças de esquerda não aceitavam o argumento de que o aumento dos salários iria provocar o aumento da natalidade, gerando uma crise de superpopulação. Desta forma, a questão dos direitos humanos (econômicos, sociais, políticos, etc.) estavam colocados juntamente com o que hoje chamamos de direito reprodutivo.

Mas, já no início do século XIX, surgiram propostas visando conciliar o aumento dos salários e melhoria das condições de vida da classe trabalhadora com a estabilidade do crescimento populacional. Com a redução das taxas de mortalidade infantil não era mais necessária uma prole numerosa para obter o número desejado de filhos sobreviventes. Portanto, a alternativa lógica proposta, não aceita no modelo malthusiano, viria da limitação da fecundidade (número médio de filhos por mulher). Essa abordagem recebeu, historicamente o nome de neomalthusianismo, visto que era uma proposta de controle populacional, mas agora pela redução do número médio de filhos nascidos vivos. Um dos primeiros pensadores e ativistas a fazer a ligação entre aumento de salários e o controle da natalidade foi Robert Owen. 
Considerado na literatura marxista como um socialista utópico, Owen se preocupava com a qualidade de vida do proletariado e foi pioneiro na educação dos filhos dos trabalhadores, além de criador da primeira cooperativa de operários. Foram seus associados, como Francis Place e Richard Carlile que publicaram as primeiras obras neomalthusianas na Inglaterra1. (MARTINEZ-ALIER; MASJUAN, 2004). Esse neomalthusianismo, gestado no seio das forças de esquerda, ganhou proeminência em agosto de 1900, quando houve a realização da primeira Conferência Internacional Neomalthusiana, em Paris, reunindo diversas personalidades dos campos científico, cultural e artístico de vários países do mundo, com o objetivo de espalhar a palavra-de-ordem "procriação consciente" e propagar os métodos anticoncepcionais disponíveis (MARTINEZ-ALIER; MASJUAN, 2004).

Uma das pessoas mais influentes das fileiras neomalthusianas da virada do século XX e que esteve presente na Conferência de Paris foi a anarquista e feminista, Emma Goldman. Ela que já tinha uma atuação destacada internacionalmente, foi editora da revista "Mother Earth", entre 1908 e 1916, nos Estados Unidos, onde defendia a ideia de que o controle da natalidade poderia diminuir a miséria humana e reduzir o peso da família numerosa, criando as condições para que as mulheres, de todas as classes sociais, obtivessem a liberdade sexual, por meio da separação consciente entre sexualidade e reprodução. Emma Goldman foi presa em 1916, por violar a lei que proibia a divulgação de informações sobre métodos contraceptivos e deportada do país² (ALVES; CORREA, 2003).

Mas estas posições neomalthusianas de cunho progressista, anarquista e de esquerda - que defendiam o uso de métodos contraceptivos, ainda que métodos mais tradicionais, como um meio para se alcançar a procriação consciente

\footnotetext{
${ }^{1} \mathrm{Em} 1825$, Owen se muda para os Estados Unidos e forma a comunidade cooperativista-comunista Nova Harmonia. Em 1835, o filho de Robert Owen, Robert Dale, publicou o livro neomalthusiano intitulado "Moral Physiology" em Nova York, e que teve várias edições nos Estados Unidos e na Inglaterra.

${ }^{2}$ Deportada, Emma Goldman foi para a União Soviética (URSS), em 1919, e juntamente com outros militantes anarquistas exerceu influência na era Lênin, ajudando os bolcheviques a implementar progressistas em relação aos métodos de regulação da fecundidade, ao aborto e à educação sexual. Mas com a ascensão de Stalin, ela deixou a URSS e publicou o livro "Minha desilusão com a Rússia" (ALVES, CORREA, 2003).
} 
(concepção muito próxima da noção atual de direito reprodutivo) - não eram as únicas concepções no movimento pelo controle da natalidade no início do século XX. Como mostraram Hodgson e Watkins (1997) havia também aqueles que defendiam o controle da natalidade como uma medida quantitativa para evitar a superpopulação e outros que defendiam o controle qualitativo da população com finalidades eugênicas de aperfeiçoamento da raça.

\section{As visões sobre população e desenvolvimento}

Nos duzentos anos após a Revolução Francesa, o debate demográfico e econômico esteve focado nos efeitos do crescimento populacional sobre o desenvolvimento, sendo que, de modo geral, o "problema populacional" era visto como um desafio e o desenvolvimento como uma solução. Todavia, nas últimas décadas os benefícios do desenvolvimento começaram a ser questionados e a própria ideia de desenvolvimento sustentável virou tema de debate e de questionamento sobre a possibilidade de um transcurso desenvolvimentista ocorrer sem degradar o meio ambiente e o respeito à biodiversidade.

\subsection{Da eugenia e controle da natalidade aos direitos reprodutivos}

O termo "eugenia" foi utilizado pela primeira vez por Francis Galton, em 1883, significando "bem-nascido", mas a ideia eugenista de melhoramento da raça é antiga e já estava presente na obra do filósofo grego Platão. A "eugenia positiva" incentivava as pessoas saudáveis ou de "classes superiores" a terem famílias numerosas, enquanto a "eugenia negativa" buscava limitar a reprodução de pessoas ou segmentos sociais com características indesejáveis. Por exemplo, a Alemanha Nazista aprovou leis que proibiram o casamento ou contato sexual de alemães com judeus, pessoas com problemas mentais, doenças contagiosas ou hereditárias. Experiências eugênicas foram realizadas pelo fascismo italiano e o militarismo japonês. Já nos anos 1930, havia muitas vozes contra os argumentos eugênicos, sendo que depois dos diversos crimes de guerra e do Holocausto provocado pelo 
nazismo, as vozes defendendo abertamente tais ideias foram silenciadas e se emudeceram (MCNICOLL, 1999).

Depois da Segunda Guerra Mundial e do processo de descolonização da Ásia e da África, com as melhorias no padrão de vida e na redução das taxas de mortalidade ocorridas nos chamados "trinta anos gloriosos" (1945-1975), as décadas de 1950 e 1960 apresentaram as maiores taxas de crescimento demográfico da história humana. Nessa conjuntura, ganharam destaque as correntes neomalthusianas preocupadas com a explosão populacional, a armadilha da pobreza devido à alta razão de dependência demográfica (maior proporção de pessoas em idade dependente em relação à proporção de pessoas em idade potencialmente ativa) e a possibilidade de uma generalizada insegurança alimentar.

Um marco do neomalthusianismo, pós Segunda Guerra, foi a publicação, em 1958, do livro "População e desenvolvimento econômico", de Coale e Hoover (1966), onde os autores argumentam que a queda das taxas de mortalidade nos países em desenvolvimento ocorreu, de forma exógena, em função da importação de tecnologias médicas e sanitárias. Nessa situação, não haveria estímulos para a queda da fecundidade e o alto crescimento demográfico e a estrutura etária jovem inviabilizaria o desenvolvimento econômico. Assim, na ausência das transformações sociais que possibilitaram a transição demográfica nos países desenvolvidos, somente políticas de controle da natalidade poderia evitar o problema da superpopulação. Desta forma, os autores propõem a instituição de políticas de controle voluntário da natalidade.

Mas o livro que teve o maior impacto na difusão da mensagem neomalthusiana foi “A Bomba Populacional”, de Paul Ehrlich (1968), onde apresentou um cenário catastrófico do crescimento da população mundial e de uma aguda crise demográfica. Para o autor, o mundo deveria ter como meta igualar as taxas de natalidade e mortalidade para chegar ao crescimento populacional zero (ZPG). Para Ehrlich, o ideal seria que a redução da natalidade ocorresse pelo uso 
voluntário de métodos contraceptivos, mas ele concordava com a aplicação de medidas compulsórias, caso as taxas de fecundidade permanecessem altas.

Nesta mesma época, o presidente dos Estados Unidos, Lyndon Johnson disse que investir cinco dólares no planejamento familiar daria maior retorno do que cem dólares investidos no desenvolvimento econômico. Este debate foi levado para a primeira Conferência Mundial de População, organizada pela ONU, em Bucareste, em 1974. Porém, os países pobres e não desenvolvidos, liderados pela China e a Índia, defenderam a prioridade dos investimentos no desenvolvimento e não no controle da natalidade. Esta também foi a posição adotada pelo Vaticano. $O$ neomalthusianismo foi derrotado e venceu a palavra de ordem: "O desenvolvimento é o melhor contraceptivo" (ALVES, 2002).

Contudo, antes da segunda Conferência Mundial de População, ocorrida na cidade do México, em 1984, houve uma reviravolta na ordem internacional sobre as questões reprodutivas. A China comunista, que estava na linha de frente contra as políticas defendidas por Paul Ehrlich adotou a política de filho único, em 1979, a política de cunho neomalthusiana mais draconiana da história. Já os Estados Unidos, seguindo os princípios neoliberais do governo Ronald Reagan, abandonaram as propostas neomalthusianas e adotaram o laissez-faire populacional (ALVES; CORREA, 2003; MARTINE; ALVES, 2015).

Evidentemente, a queda das taxas de mortalidade, especialmente, a queda acentuada da mortalidade infantil aumenta a sobrevivência das crianças e jovens e torna as altas taxas de fecundidade, até certo ponto, conflitantes com o novo quadro populacional, decorrente da transição demográfica. Os desenvolvimentistas acreditam que o avanço da renda e da educação provocam inevitavelmente a redução do tamanho da família. Mas os neomalthusianos dizem que se não houver queda da fecundidade não haverá desenvolvimento. O fato é que, por caminhos diferentes, tanto o neomalthusianismo de direita, quanto o neomalthusianismo de esquerda defendem a ampla disponibilidade de métodos contraceptivos modernos. A diferença é que os segundos advogam a democratização do acesso de forma a 
garantir a autodeterminação reprodutiva, condenando todos as políticas coercitivas.

Assim, apesar de todos estes avanços, os direitos reprodutivos só foram reconhecidos depois da Conferência de Viena e formam aprovados na Conferência Internacional de População e Desenvolvimento (CIPD), realizada na cidade do Cairo, em 1994. Na IV Conferência Mundial das Mulheres, ocorrida em Beijing, em 1995, os direitos reprodutivos foram reafirmados. A novidade foi a adoção de princípios que se contrapõe, por um lado, a qualquer tipo de controle coercitivo da natalidade e, por outro, a qualquer tipo de imposição natalista que implique na proibição de uso de métodos contraceptivos e na restrição da autonomia feminina. No Programa de Ação da CIPD do Cairo (CORREA; ALVES; JANNUZZI, 2006), os direitos reprodutivos foram definidos da seguinte forma:

Os direitos reprodutivos se ancoram no reconhecimento do direito básico de todo casal e de todo indivíduo de decidir livre e responsavelmente sobre o número, o espaçamento e a oportunidade de ter filhos e de ter a informação e os meios de assim o fazer, e o direito de gozar do mais elevado padrão de saúde sexual e reprodutiva. Inclui também seu direito de tomar decisões sobre a reprodução, livre de discriminação, coerção ou violência (§ 7.3).

Os direitos reprodutivos são, portanto, o filho caçula da Declaração Universal dos Direitos Humanos. A gravidez indesejada sempre diminui onde esses direitos são respeitados3. Porém, são exatamente as populações mais pobres do mundo que carecem dos meios de acesso aos serviços de saúde reprodutiva. Relatório do Guttmacher Institute, mostra que o não atendimento da demanda por métodos contraceptivos nas regiões menos desenvolvidas, atinge 214 milhões de mulheres em idade reprodutiva, que querem evitar a gravidez, mas não têm como garantir a autodeterminação reprodutiva (DARROCH, 2017).

\footnotetext{
${ }^{3}$ O Irã é um exemplo de país que tinha uma taxa de fecundidade muito alta e com grande percentagem de gravidez não planejada. No entanto, em dezembro de 1989, o governo iraniano, sob a liderança do aiatolá Khomeini, inverteu radicalmente a política populacional e lançou um novo programa de planejamento familiar, que possibilitou a redução da Taxa de Fecundidade Total (TFT) para 5,5 filhos por mulher, em 1988, 2,8 filhos em 1996 e para 2,1 filhos em 2000. Em apenas 15 anos a TFT caiu de 6 filhos por mulher para o nível de reposição (2,1 filhos). Foi a transição da fecundidade mais rápida já registrada (ABBASI-SHAVAZI, M. J. et. al. 2009).
} 


\subsection{A encíclica Humanae Vitae e os direitos reprodutivos}

No debate entre população e desenvolvimento, envolvendo questões reprodutivas, há um ator importante que não pode ser ignorado: a religião. O documento religioso que teve maior impacto na discussão populacional foi a encíclica Humanae Vitae ("Da vida humana") escrita pelo Papa Paulo VI (1968), por coincidência no mesmo ano em que Paul Ehrlich (1968) publicou o livro "A bomba populacional". A encíclica inclui o subtítulo "Sobre a regulação da natalidade" e define a postura da Igreja Católica sobre as questões de reprodução e sexualidade.

A encíclica Humanae Vitae reafirma a doutrina da natureza do matrimônio (“instituição sapiente do Criador”) como um sacramento indissolúvel realizado com finalidade procriativa. Sobre as características do amor conjugal, a encíclica diz:

É, antes de mais, um amor plenamente humano, quer dizer, ao mesmo tempo espiritual e sensível" [...]. É depois, um amor total [...]. É, ainda, amor fiel e exclusivo, até à morte [...]. É, finalmente, amor fecundo que não se esgota na comunhão entre os cônjuges, mas que está destinado a continuar-se suscitando novas vidas (§ 9).

Mas a Humanae Vitae também trata da "paternidade responsável", que significa o "domínio da razão" em relação "às tendências do instinto e das paixões". O texto parece abrir espaço para a regulação da fecundidade, se houver motivos graves:

Em relação às condições físicas, econômicas, psicológicas e sociais, a paternidade responsável exerce-se tanto com a deliberação ponderada e generosa de fazer crescer uma família numerosa, como com a decisão, tomada por motivos graves e com respeito pela lei moral, de evitar temporariamente, ou mesmo por tempo indeterminado, um novo nascimento (§ 10).

Mas a encíclica não deixa dúvidas de que, fora os casos excepcionais, os casais devem evitar o livre arbítrio e obedecer aos desígnios de Deus: 
Na missão de transmitir a vida, eles não são, portanto, livres para procederem a seu próprio bel-prazer, como se pudessem determinar, de maneira absolutamente autônoma, as vias honestas a seguir, mas devem, sim, conformar o seu agir com a intenção criadora de Deus, expressa na própria natureza do matrimônio e dos seus atos e manifestada pelo ensino constante da Igreja (§ 10).

Para respeitar a natureza e a finalidade do ato matrimonial, os esposos devem se unir em "casta intimidade" e respeitar os dois significados do ato conjugal: o significado unitivo e o significado procriador (§ 12). Assim, a encíclica Humanae Vitae condena os métodos artificiais de regulação da fecundidade:

Em conformidade com estes pontos essenciais da visão humana e cristã do matrimônio, devemos, uma vez mais, declarar que é absolutamente de excluir, como via legítima para a regulação dos nascimentos, a interrupção direta do processo generativo já iniciado, e, sobretudo, o aborto querido diretamente e procurado, mesmo por razões terapêuticas. É de excluir de igual modo, como o Magistério da Igreja repetidamente declarou, a esterilização direta, quer perpétua quer temporária, tanto do homem como da mulher. É, ainda, de excluir toda a ação que, ou em previsão do ato conjugal, ou durante a sua realização, ou também durante o desenvolvimento das suas consequências naturais, se proponha, como fim ou como meio, tornar impossível a procriação (§ 14).

Ao mesmo tempo a encíclica reconhece a legitimidade dos métodos naturais de regulação da fecundidade:

Se, portanto, existem motivos sérios para distanciar os nascimentos, que derivem ou das condições físicas ou psicológicas dos cônjuges, ou de circunstâncias exteriores, a Igreja ensina que então é lícito ter em conta os ritmos naturais imanentes às funções geradoras, para usar do matrimônio só nos períodos infecundos e, deste modo, regular a natalidade, sem ofender os princípios morais que acabamos de recordar. (§ 16).

Se estas posições da Igreja Católica foram úteis para combater as políticas coercitivas de controle da natalidade, elas colocaram uma dificuldade para os fiéis que desejavam espaçar o intervalo entre os nascimentos e até mesmo limitar o tamanho da prole, diante da queda das taxas de mortalidade. Diferentemente da sociedade agrária e rural, a sociedade urbano-industrial desencadeia processos que mudam a relação custo/benefício dos filhos e, em geral, reverte o fluxo intergeracional de riquezas (CALDWELL, 1982). Assim, manter altas taxas de 
fecundidade e uma família numerosa tornou-se incompatível com a nova realidade social e intergeracional.

Como já visto anteriormente, os métodos contraceptivos podem ser utilizados como meios de coerção para o controle autoritário da população ou de determinados grupos populacionais, mas também podem ser utilizados com meio de evitar uma gravidez intempestiva e garantir a autonomia reprodutiva das mulheres e dos casais.

A comunidade internacional debateu estas questões nas duas primeiras Conferências Mundiais de População, porém, foi na Conferência Internacional sobre População e Desenvolvimento que os direitos reprodutivos passaram a fazer parte de um documento internacional aprovado pela maioria dos países do mundo. Todavia, nos debates preparatórios para a CIPD do Cairo, o Vaticano se posicionou firmemente contra o conceito de direitos reprodutivos, reafirmando os princípios expostos na encíclica Humanae Vitae e desconsiderando o fato de que a população mundial passou de 3 bilhões de habitantes em 1960 para 5,5 bilhões, em 1994, e continuava crescendo (ALVES, 2000). Enquanto setores controlista, tanto a nível internacional (EHRLICH, 1968), quanto nacional (AGUINAGA, 1980), falavam em "explosão populacional", vários bispos da Conferência Nacional dos Bispos do Brasil (CNBB) se posicionaram contra o "inverso demográfico", a "desnatalização", o "terrorismo populacional" e a chamada "cultura da morte" (ALVES, 2000).

Num posicionamento antineomalthusiano, os bispos passam a combater os métodos contraceptivos, a esterilização e, principalmente, o aborto. O Programa de Ação da CIPD do Cairo foi criticado, nas palavras de Dom Lucas Moreira Neves, na época Cardeal-arcebispo de Salvador e primaz do Brasil, da seguinte maneira:

A terceira observação crítica - a mais severa - contra o 'esboço de documento final', é que, nele, o afã controlista, se não propugna pela esterilização em massa de mulheres férteis e até pelo aborto, pelo menos admitem estas práticas como métodos válidos para a desnatalização. É visível que conceitos e expressões como 'direitos sexuais e reprodutivos' 
(usados mais de cem vezes no 'Draft'), 'sexo seguro', 'maternidade segura', 'saúde reprodutiva', cobrem, na verdade, a intenção de legalizar e legitimar o 'aborto seguro'. Isso equivale a colocar a Conferência sob signo sinistro de uma genuína "cultura da morte" (DOM NEVES, 1994, p.1).

Mas o conceito de direitos reprodutivos foi gestado na perspectiva dos direitos humanos, em resposta tanto às questões demográficas, quanto às questões de saúde. No primeiro caso, os direitos reprodutivos se opõem à imposição de metas populacionais e, no segundo caso, reforça o conceito de saúde integral da mulher. Segundo a definição estabelecida no Plano de Ação da CIPD, do Cairo:

Os direitos reprodutivos abrangem certos direitos humanos já reconhecidos em leis nacionais, em documentos internacionais sobre direitos humanos em outros documentos consensuais. Esses direitos se ancoram no reconhecimento do direito básico de todo casal e de todo indivíduo de decidir livre e responsavelmente sobre o número, o espaçamento e a oportunidade de ter filhos e de ter a informação e os meios de assim o fazer, e o direito de gozar do mais elevado padrão de saúde sexual e reprodutiva. Inclui também seu direito de tomar decisões sobre a reprodução, livre de discriminação, coerção ou violência (§ 7.3).

Embora a crítica religiosa ao controlismo autoritário seja correta, a oposição aos direitos reprodutivos não faz muito sentido no contexto de um Estado Laico que precisa, por exemplo, fornecer os meios e as informações para evitar a gravidez indesejada, a gravidez precoce entre as adolescentes e o sexo seguro para evitar doenças sexualmente transmissíveis.

Existem setores da Igreja Católica que questionam as posições da Santa Sé contra os direitos reprodutivos. Em editorial, a revista National Catholic Reporter (2015) afirma que a encíclica Humanae Vitae tem sido um sério impedimento à autoridade católica e que o seu texto criou um abismo entre os prelados e os padres, entre a hierarquia e os fiéis. Ou seja, segundo setores da própria igreja Católica, há vozes a favor de rever a doutrina e as práticas sobre a reprodução 
humana4. Por exemplo, métodos eficientes de contracepção podem evitar a gravidez não planejada e o aborto.

$\mathrm{Na}$ prática, o desrespeito aos direitos reprodutivos leva a um processo acumulativo de desrespeito aos direitos ambientais, pois o crescimento das atividades ecúmenas (ocorridas em áreas geográficas permanentemente habitadas pelo ser humano) tende a provocar a diminuição das áreas anecúmenas (aquelas não habitadas pelo ser humano), afetando a reprodução da vida selvagem e a saúde dos ecossistemas.

\section{A ecologia biocêntrica como concepção avançada dos direitos ambientais}

Os pensadores iluministas que inspiraram a Revolução Francesa não imaginaram que a implantação dos direitos humanos fosse se chocar tão frontalmente com o equilíbrio e a saúde do meio ambiente. Mas as primeiras décadas do século XXI apontam para uma contradição crescente entre o progresso civilizatório e o regresso ambiental. No entanto, a sociedade depende da natureza e não o contrário. Como afirmou Milaré (1996):

A Natureza precede ao próprio ser humano. Por isso as demais formas de vida apresentam um significado próprio em si mesmas, enquanto expressão criadora de Deus ou da natureza, conforme o posicionamento religioso de cada um (MILARÉ, 1996, p. 114.).

Na mesma linha, o escritor Eduardo Galeano (2008), preocupado com a degradação da natureza e inspirado pela Constituição do Equador, chega até a propor um acréscimo nos Dez Mandamentos:

\footnotetext{
${ }^{4}$ O jornalista Robert McClory (1995), no livro "Turning Point: The Inside Story of the Papal Birth Control Commission, and how Humanae Vitae Changed the Life of Patty Crowley and the Future of the Church" mostra que a "Comissão Papal do controle da natalidade", criada por iniciativa do Concílio Vaticano II, após longo debate, concluiu que a contracepção artificial deveria ser considerada moralmente aceitável para os casais. Após uma votação por 52 votos a 4, encaminhou um relatório com a posição da maioria para o Papa Paulo VI recomendando a aceitação dos métodos contraceptivos artificiais. Porém, o pequeno número de membros da Comissão que se opunham a essa mudança, em conjunto com funcionários conservadores do Vaticano, construiu um relatório minoritário contra as mudanças no dogma da Igreja sobre contracepção. Este relatório minoritário constituiu a base da encíclica Humanae Vitae.
} 
A natureza tem muito a dizer, e já vai sendo hora de que nós, seus filhos, paremos de nos fingir de surdos. E talvez até Deus escute o chamado que soa saindo deste país andino, e acrescente o décimo primeiro mandamento, que ele esqueceu nas instruções que nos deu lá do monte Sinai: 'Amarás a natureza, da qual fazes parte'. (23/04/2008).

A citação acima nos leva a ressaltar a diferença entre a abordagem sobre o meio ambiente nas Constituições do Brasil e do Equador. O Art. 225 da Constituição Brasileira, de 1988, diz:

Todos têm direito ao meio ambiente ecologicamente equilibrado, bem de uso comum do povo e essencial à sadia qualidade de vida, impondo-se ao Poder Público e à coletividade o dever de defendê-lo e preservá-lo para as presentes e futuras gerações (CONSTITUIÇÃO Federal, 1988).

Enquanto a Constituição brasileira apresenta uma visão instrumentalista do meio ambiente, a Constituição do Equador, pelo menos em tese, apresenta uma visão de defesa de direitos intrínsecos da natureza. O Art. 71, diz:

La naturaleza o Pacha Mama, donde se reproduce y realiza la vida, tiene derecho a que se respete integralmente su existencia y el mantenimiento y regeneración de sus ciclos vitales, estructura, funciones y procesos evolutivos. Toda persona, comunidad, pueblo o nacionalidad podrá exigir a la autoridad pública el cumplimiento de los derechos de la naturaleza. Para aplicar e interpretar estos derechos se observarán los principios establecidos en la Constitución, en lo que proceda. El Estado incentivará a las personas naturales y jurídicas, y a los colectivos, para que protejan la naturaleza, y promoverá el respeto a todos los elementos que forman un ecosistema. (CONSTITUCIÓN de la República del Ecuador, 2008).

O Art. 71 da Constituição do Equador (2008) teve grande impacto em todo o continente, pois resgatou a ideia de uma sustentabilidade biocêntrica. As raízes do biocentrismo são antigas, podendo ser encontradas nos textos clássicos das filosofias indiana e chinesa, mas que começou a tomar forma no Ocidente a partir da obra do escritor transcendentalista Henry Thoreau, cujo ducentésimo aniversário de nascimento ocorreu dia 12 de julho de 2017. Thoreau (2007) faz uma crítica aos governos ilegítimos, ao desenvolvimento consumista e ao processo de degradação do meio ambiente. Thoreau se tornou pioneiro do movimento 
ambientalista e suas obras passaram a ter grande influência sobre os amantes da natureza e os admiradores e defensores da vida selvagem.

Essa linha de pensamento foi aprofundada pelos defensores da Ecologia Profunda (Deep Ecology), que é um conceito filosófico que busca superar o antropocentrismo, indo na raiz dos problemas ambientais para defende os direitos de toda a comunidade biótica. Em 1984, Arne Næss e George Sessions publicaram o texto "Basic Principles of Deep Ecology" onde enumeram os oito princípios da plataforma da Ecologia Profunda, mostrando que a natureza tem valor em si própria (valor intrínseco).

A Ecologia Profunda nunca chegou a ser considerada uma alternativa viável nos Fóruns Internacionais e no Tratados Globais e nunca fez parte do mainstream acadêmico. Mas a preocupação com a crise ecológica e os direitos ambientais cresceu com a publicação de diversos livros e estudos sobre os impactos humanos sobre o meio ambiente (CARSON, 1962; BOUDING, 1966; DALY, 1973; GEORGESCU-ROEGEN, 1971; ODUM, 1971).

Mas o livro que teve a maior repercussão de público foi "Limites do Crescimento, um relatório para o Projeto do Clube de Roma sobre o Dilema da Humanidade", liderado por Donella e Dennis Meadows (1978, originalmente de 1972). Os autores constroem um modelo para investigar cinco grandes tendências de interesse global e buscam compreender suas implicações num horizonte de cem anos. O livro obteve grande reconhecimento, mas também recebeu muitas críticas. Em geral, os críticos acusam as posições do livro e do Clube de Roma, como sendo posicionamentos neomalthusianos a favor do controle populacional. A principal conclusão do livro está resumida no seguinte parágrafo:

Se as atuais tendências de crescimento da população mundial, industrialização, poluição, produção de alimentos e diminuição de recursos naturais continuarem imutáveis, os limites de crescimento neste planeta serão alcançados algum dia dentro dos próximos cem anos. $\mathrm{O}$ resultado mais provável será um declínio súbito e incontrolável, tanto da população quanto da capacidade industrial (MEADOWS; MEADOWS, 1978, p. 20). 
De fato, as contradições entre as conquistas do desenvolvimento e as derrotas do meio ambiente estão se aprofundando. A ameaça de um colapso civilizacional e ambiental não está afastada, o que torna urgente a busca de soluções para articular a defesa dos direitos humanos e a defesa dos direitos ambientais em sua concepção mais ampla.

\section{0 desenvolvimento sustentável e os direitos ambientais}

A CIPD do Cairo, além de aprovar a concepção dos direitos reprodutivos, reforçou também a formulação que define o desenvolvimento como um direito das nações e, em consonância com a Conferência das Nações Unidas sobre o meio ambiente e desenvolvimento (Eco-92), aprovou a concepção do desenvolvimento sustentável. Contudo, desenvolvimento e sustentabilidade nem sempre estão do mesmo lado, como supõem as formulações da ONU.

\subsection{As limitações do conceito de desenvolvimento sustentável}

A formulação mais difundida do desenvolvimento sustentável é aquela do Relatório Brundtland (1987), que o definiu da seguinte forma: "o desenvolvimento que satisfaz as necessidades presentes, sem comprometer a capacidade das gerações futuras de suprir suas próprias necessidades” (p. 49). Essa definição foi utilizada nos documentos das Conferências seguintes, como a Eco-92 e a CIPD-94. Em 2002 foi realizada a Cúpula Mundial sobre Desenvolvimento Sustentável em Joanesburgo, na África do Sul, (conhecida como Rio+10 ou Cúpula da Terra II), que discutiu os avanços alcançados pela Agenda 21 e outros acordos da Cúpula de 1992, além de estabelecer as três dimensões do desenvolvimento sustentável: econômica, o social e ambiental.

A ideia de um desenvolvimento economicamente inclusivo, socialmente justo e ambientalmente sustentável passou a vigorar no cenário internacional e orientou as resoluções da Conferência das Nações Unidas sobre Desenvolvimento 
Sustentável (Rio+20), realizada em 2012, também na cidade do Rio de Janeiro, e que deliberou pelo lançamento de um processo intergovernamental para a criação dos Objetivos de Desenvolvimento Sustentável (ODS)5.

Entre a realização da Rio+20 e a definição dos ODS, em documento assinado por 193 líderes mundiais, o tripé da sustentabilidade foi substituído por cinco prioridades (conhecidos como 5 P's), consideradas de importância crítica para a humanidade: Pessoas, Planeta, Prosperidade, Paz e Parcerias. Os cinco P's (UNITED NATIONS, 2015) foram apresentados como prioridades equidistantes, projetadas dentro de um círculo, cujo centro é um pentágono, representando o "desenvolvimento sustentável". No topo do desenho estão colocadas as Pessoas (erradicação da pobreza), no nível intermediário estão o Planeta (recursos naturais e clima) e a Prosperidade (bem-estar humano) e, na base do círculo, estão a Paz (sociedades pacíficas, justas e inclusivas) e as Parcerias (governança global sólida).

De fato, desde o Relatório Brundtland, de 1987, até a aprovação dos ODS, em 2015, houve uma ampliação do conceito de desenvolvimento sustentável que passou de um triângulo (econômico, social e ambiental) para um pentágono (os cinco P's). Mas a despeito da maior abrangência, os ODS continuam apoiados na estratégia do crescimento econômico. Por exemplo, o objetivo \# 8.1, propõe: "Sustentar o crescimento econômico per capita, de acordo com as circunstâncias nacionais e, em particular, pelo menos um crescimento anual de 7\% do PIB nos países menos desenvolvidos" (UNITED NATIONS, 2015, p.19).

Porém, como mostra a Escola da Economia Ecológica é impossível manter o crescimento ilimitado em um Planeta finito, regido pela $2^{\mathrm{a}}$ Lei da Termodinâmica que aponta que a civilização se baseia no fluxo metabólico entrópico e no modelo "Extrai-Produz-Descarta" (CAVALCANTI, 2012). Para manter a crescente oferta de bens e serviços, o modelo econômico em vigor retira insumos da natureza, que

\footnotetext{
${ }^{5}$ A elaboração dos ODS contou com o apoio e a colaboração de governos, sociedade civil, empresários, das diversas agências do Sistema ONU e de milhares de pessoas ao redor do mundo. Em setembro de 2015, a Assembleia Geral aprovou os Objetivos de Desenvolvimento Sustentável, com 17 objetivos e 169 metas, constituindo um dos eixos da Agenda 2030 da ONU.
} 
depois de consumidos se tornam lixo. A poluição que acompanha esse processo afeta o meio ambiente antes, durante e depois da produção e tudo que está ao seu redor.

A descrença quase generalizada que existia há alguns anos sobre as mudanças ambientais, perda de biodiversidade e vários outros problemas ambientais, tem sido tomada de sobressalto com as evidências. Apesar de sua complexidade, vale aqui chamar atenção para algumas questões importantes como o aumento da extração de recursos naturais e o posterior descarte de resíduos sólidos, lixo e poluição.

O relatório "Global Material Flows And Resource Productivity" (UNEP, 2016) mostra que a extração de recursos naturais globais aumentou três vezes nos últimos 40 anos. A quantidade de matérias-primas extraídas do seio da natureza subiu de 22 bilhões de toneladas em 1970 para 70 bilhões de toneladas em 2010 . O aumento do uso de materiais globais acelerou rapidamente nos anos 2000, com o crescimento das economias emergentes, em especial com o crescimento da China. O crescimento na extração de recursos naturais passou de 7 toneladas per capita em 1970 para 10 toneladas per capita em 2010.

O crescimento das atividades antrópicas fez com que a humanidade ultrapassasse a capacidade de carga do Planeta, conforme pode ser atestado pela Global Footprint Network (2017), que apresenta duas medidas para se avaliar o impacto humano sobre o meio ambiente e a disponibilidade de "capital natural". A Pegada Ecológica serve para avaliar o impacto que o ser humano exerce sobre a biosfera e a Biocapacidade avalia o montante de terra e água, biologicamente produtivo, para prover bens e serviços do ecossistema à demanda humana por consumo (o que é equivalente à capacidade regenerativa da natureza).

A pegada ecológica per capita do mundo, em 1961, era de 2,27 hectares globais (gha) e a biocapacidade per capita era de 3,12 gha. Para uma população de 3,1 bilhões de habitantes, o impacto da pegada global do ser humano era de 6,98 
bilhões de gha, representando apenas 73\% dos 9,53 bilhões de hectares globais da biocapacidade disponível naquele momento. Portanto, havia um superávit ou reserva ecológica. A economia cabia na sustentabilidade da ecologia. Mas com o crescimento da população e do consumo, a reserva ecológica foi sendo reduzida e, a partir de 1970, o superávit se transformou em déficit ambiental. Em 2013, a pegada ecológica per capita do mundo subiu para 2,87 gha e a biocapacidade caiu para 1,71 gha. Para uma população mundial de 7,2 bilhões de habitantes, o déficit ambiental chegou a 68\% em 2013.

Outra metodologia que ajuda a avaliar a capacidade de carga da Terra foi apresentada no em um artigo que trata das "Fronteiras Planetárias (ROCKSTRÖM, 2009). O artigo traça um quadro dos limites planetários e define um espaço operacional seguro para a humanidade com base na análise dos processos biofísicos intrínsecos que regulam a estabilidade do Sistema Terra. O estudo identifica nove dimensões centrais para a manutenção de condições de vida decentes para as sociedades humanas e o meio ambiente, indicando que os limites já foram ultrapassados em 3 dimensões e estavam se agravando nas demais.

Em outro artigo atualizado e publicado na Revista Science (STEFFEN, 2015), quatro das nove fronteiras planetárias foram ultrapassadas: Mudanças climáticas; Perda da integridade da biosfera; Mudança no uso da terra; Fluxos biogeoquímicos (fósforo e nitrogênio). Duas delas, a Mudança climática e a Integridade da biosfera, são o que os cientistas chamam de "limites fundamentais" e tem o potencial para conduzir o Sistema Terra a um novo estado que pode ser substancialmente e persistentemente transgredido, sendo que o agravamento destas duas fronteiras fundamentais pode levar a civilização ao colapso.

De fato, a lista de problemas ambientais é bastante extensa. Perda de florestas, destruição dos mangues, degradação dos solos, erosão, desertificação; Degradação das águas, poluição dos rios, lagos e oceanos, agrotóxicos, acidificação, eutrofização, crise hídrica, guerra pela água, naufrágio dos deltas dos rios, fim dos aquíferos fósseis e degradação dos aquíferos renováveis; Aumento da temperatura 
dos oceanos, sobrepesca, acidificação, destruição dos corais, acúmulo de plásticos, diminuição da vida marinha, etc. Tudo isto contribui para a perda de biodiversidade.

\subsection{O Antropoceno e a sexta extinção em massa das espécies}

A interferência humana sobre a natureza adquiriu tal dimensão que o vencedor do prêmio Nobel de química, Paul Crutzen, propôs a utilização do termo Antropoceno, para designar uma nova Era geológica, em que o sistema econômico global e o crescimento das atividades antrópicas são o principal fator responsável pela perda da biodiversidade, pela degradação dos ecossistemas e pela redução da vida selvagem (ISSBERNER; LÉNA, 2017).

Elizabeth Kolbert (2015), no livro “A Sexta Extinção: Uma história Não Natural”, mostrou que a grande aceleração das atividades econômicas alterou a vida no planeta de forma inédita e está provocando a eliminação de um grande número de espécies que já habitam a Terra antes do surgimento do Homo Sapiens. A autora acompanhou o trabalho de cientistas de diversas especialidades para mostrar o grau de perda de biodiversidade, analisando a situação de doze espécies, algumas já em extinção e outras correndo o risco de desaparecerem em um horizonte próximo. Os cenários não são animadores e o livro mostra isso com sólidas evidências.

Na mesma linha, o premiado biólogo Edward Osborne Wilson denomina o quadro de perda de biodiversidade de "holocausto biológico". Ele propõe uma estratégia para destinar metade do planeta exclusivamente para a proteção dos animais. O plano de conservação chamado "Half Earth", inclui a criação de cadeias de corredores ininterruptos de vida selvagem, alguns deles grandes o bastante para abrigar parques nacionais de biodiversidade, idealizados para impedir o desaparecimento de espécies. Tais medidas ajudariam os animais a reagir aos efeitos das mudanças climáticas por meio da migração e também evitariam isolamento em ilhas sem conexão com outros habitates (MACIEL, 2014). 
O relatório Planeta Vivo 2016, da World Wild Foundation (WWF, 2016) apresenta o Índice Global Planeta Vivo indicando uma queda de $58 \%$ na população de animais selvagens no mundo entre 1970 e 2012. Até 2020, a perda pode alcançar a impressionante cifra de dois terços. Ou seja, 2 em cada 3 animais serão extintos num prazo de 50 anos. As espécies que vivem em lagos, rios e pântanos foram as que mais sofreram reduções e que continuarão sofrendo até 2020. Segundo o relatório, as principais causas desse declínio são as atividades antrópicas, como a destruição de habitats, o tráfico de animais selvagens, a poluição e as mudanças climáticas (WWF, 2016).

A situação atual é grave, pois o mundo não só desrespeita os direitos ambientais mas ameaça a própria existência das espécies. Estudo recente publicado na revista da Academia Nacional de Ciências dos EUA reforça as evidências da $6^{a}$ extinção em massa das espécies, chamando a atenção para a perda maciça da vida selvagem, o que os autores denominam "aniquilação biológica" (CEBALLOS, 2017),

Portanto, os Direitos Humanos não deveriam estar em contradição e em conflito com os direitos da Terra e os direitos da biodiversidade. Sem a vida da Terra não existiria vida humana. A humanidade não tem como se alimentar, por exemplo, sem os insetos polinizadores que garantem a produção agrícola. A dignidade não é exclusividade dos seres humanos. É preciso romper com a ideologia antropocêntrica que considera as pessoas como as únicas sujeitas de direito. Como mostrou o escritor Leonardo Boff (2010):

A Terra é um superorganismo vivo, Gaia, que se autorregula para ser sempre apta para manter a vida no planeta. A própria biosfera é um produto biológico, pois se origina da sinergia dos organismos vivos com todos os demais elementos da Terra e do cosmos. Criaram o habitat adequado para a vida, a biosfera. Portanto, não há apenas vida sobre a Terra. A Terra mesma é viva e como tal possui um valor intrínseco e deve ser respeitada e cuidada como todo ser vivo. Este é um dos títulos de sua dignidade e a base real de seu direito de existir e de ser respeitada como os demais seres (BOFF, 2010, p. 1). 
Desta forma, os Direitos humanos só serão efetivos quando se respeitar os direitos da Terra e da biodiversidade. O desafio é garantir os direitos humanos sem desrespeitar os direitos da comunidade biótica. Uma proposta desenhada para conciliar os direitos humanos com os direitos ambientais foi elaborada por Raworth (2017), que, por meio da representação de uma rosquinha (Donut), descreve dois anéis, onde o anel interior apresenta as dimensões sociais necessárias para o bem-estar (Direitos Humanos) e o anel exterior representa as fronteiras planetárias (Direitos ambientais). A área entre os dois anéis é o chamado "espaço ecologicamente seguro e socialmente justo" no qual a humanidade deveria se autolimitar e viver de maneira harmoniosa com a natureza e as demais espécies vivas do Planeta.

\section{A igreja católica e os direitos ambientais}

Para buscar um eixo comum em todas as agendas relacionadas aos direitos humanos e os direitos ambientais, a ONU estabeleceu o que se conhece como Agenda 2030 da Organização das Nações Unidas. Esta agenda foi definida em 2015, no septuagésimo aniversário da entidade, com a realização de três grandes eventos tratando dos temas sobre desenvolvimento sustentável, formas de mitigação das mudanças climáticas e das crises humanitárias ${ }^{6}$ : Neste ano fundamental, o Papa Francisco lançou a "Carta encíclica Laudato Si': sobre o cuidado da casa comum”, no dia 18 de junho de 2015. A encíclica veio em hora oportuna, pois trata dos grandes desafios da humanidade e da natureza, englobados nos temas da pobreza e da exclusão econômica, desenvolvimento sustentável e degradação do meio ambiente, mudanças climáticas e aquecimento global, devendo contribuir para o engajamento dos cristãos, e demais cidadãos do mundo, na defesa do “cuidado da casa comum”. Sem dúvida é uma grande contribuição à justiça ambiental.

\footnotetext{
${ }^{6}$ 1) Terceira Conferência Internacional sobre Financiamento para o Desenvolvimento, ocorrida em Addis Abeba, entre os dias 13 e 16 de julho; 2) Cúpula do Desenvolvimento Sustentável da ONU, em Nova lorque, EUA, de 25 a 27 de setembro, para aprovação dos ODS; 3) 21a Conferência do Clima, Paris, de 30 de novembro a 11 de dezembro, onde se aprovou o Acordo de Paris visando diminuir a emissão de gases de efeito estufa para limitar o aumento da temperatura global em $2 \stackrel{\circ}{\mathrm{C}}$ até 2100 .
} 
Uma das novidades mais destacadas da encíclica Laudato Sí refere-se à Ecologia Integral, conceito que fundamenta a ideia de que tudo está interligado no mundo. A ecologia integral reconhece que a humanidade enfrenta uma crise estrutural em múltiplas dimensões: um grande contingente de pessoas vivendo na pobreza, disparidades extremas de renda, o aumento da competição por recursos (incluindo energia, terra e água), ecossistemas severamente degradados, Estadosnação falidos e mudanças climáticas cada vez mais fora de controle. É a primeira vez que a Santa Sé estabelece uma relação tão estreita e interligada entre as condições econômicas, a justiça social e a ecológica.

O Papa tem falado sobre o direito das populações excluídas e os direitos de cidadania - os 3 Ts: “Teto, Terra e Trabalho", mas de forma interligada com a defesa dos ecossistemas e o combate ao aquecimento global. Ele tem afirmado vigorosamente sobre a proteção do meio ambiente e o fim à exclusão social, sendo um ator fundamental na defesa dos ODS e do Acordo de Paris sobre as mudanças climáticas. Nesse sentido, a encíclica Laudato Si’ se transformou em um documento essencial para a causa ambiental ao articular religião, direitos humanos e direitos ambientais. Como mostrou Simões (2015):

Trata-se de um posicionamento religioso, ético e moral sobre a crise ambiental e sobre as consequências para a sociedade como um todo. E está alinhada a várias encíclicas e declarações dos sumos pontífices antecessores do Papa Francisco e que mostram a preocupação da exploração do homem pelo homem e da natureza pelo homem. É como o Papa Leão XIII já exprimiu na encíclica Rerum novarum no final do século XIX. Enfatiza que os mais pobres, os menos providos, serão, como sempre, os mais afetados pelos impactos das mudanças climáticas globais. Laudato Si' ainda reflete o conhecimento científico atualizado com a questão das mudanças do clima, mostrando que o Vaticano reconhece a ciência como uma luz no meio da escuridão (p.19).

Porém, três meses depois, o Papa Francisco deu um passo à frente em relação aos direitos da natureza, no discurso que fez na Cúpula dos ODS, onde assumiu uma postura mais próxima da Ecologia Profunda. Mesmo considerando que o ser humano é portador de uma "dignidade especial", o Papa falou também em "Direito do Ambiente" e afirmou que a natureza "possui em si mesma um valor 
de existência”. O discurso do Papa na ONU, em setembro de 2015, promoveu uma aproximação entre a Ecologia Integral e a Ecologia Profunda, como pode ser visto neste trecho do discurso:

Antes de mais nada, é preciso afirmar a existência dum verdadeiro «direito do ambiente», por duas razões. Em primeiro lugar, porque como seres humanos fazemos parte do ambiente. Vivemos em comunhão com ele, porque o próprio ambiente comporta limites éticos que a ação humana deve reconhecer e respeitar. O homem, apesar de dotado de «capacidades originais [que] manifestam uma singularidade que transcende o âmbito físico e biológico» (Enc. Laudato si', 81), não deixa ao mesmo tempo de ser uma porção deste ambiente. Possui um corpo formado por elementos físicos, químicos e biológicos, e só pode sobreviver e desenvolver-se se o ambiente ecológico lhe for favorável. Por conseguinte, qualquer dano ao meio ambiente é um dano à humanidade. Em segundo lugar, porque cada uma das criaturas, especialmente seres vivos, possui em si mesma um valor de existência, de vida, de beleza e de interdependência com outras criaturas. Nós cristãos, juntamente com as outras religiões monoteístas, acreditamos que o universo provém duma decisão de amor do Criador, que permite ao homem servir-se respeitosamente da criação para o bem dos seus semelhantes e para a glória do Criador, mas sem abusar dela e muito menos sentir-se autorizado a destruí-la. E, para todas as crenças religiosas, o ambiente é um bem fundamental (cf. ibid., 81). (Papa Francisco, 25/09/2015).

Mas, a despeito de todos os avanços, os direitos intrínsecos da natureza e os direitos dos animais estão longe de serem reconhecidos pelas legislações nacionais e internacional. Evidentemente, não faz sentido os animais passarem por todas as gerações de direitos, tal como aconteceu historicamente na modernidade. Não faz sentido, para os animais, os direitos civis e políticos, como o direito de voto e a liberdade religiosa. Mas alguns direitos fundamentais são essenciais, especialmente para os animais sencientes, como direito à liberdade, à integridade física, e à vida.

Segundo Tom Regan (2003), existem várias religiões que respeitam total ou parcialmente estes direitos e adotam uma dieta vegetariana, como o hinduísmo, jainismo e o budismo. Mesmo pessoas ou setores do judaísmo e do cristianismo também adotam uma prática vegetariana, ou até mesmo vegana. Uma prática cada vez mais condenável é a violência que os animais são submetidos nas fazendas antes e durante seu abate. No texto "Especismo religioso", Oliveira (2011) pergunta e reflete sobre a relação entre religião e o direito dos animais: 
Por que o apelo a conotações religiosas no âmbito do Direito dos Animais? Porque a teoria dos direitos animais, consoante concebida por muitos, não é indiferente à religião: a religião é tida como um fator elementar ou mesmo indispensável a fim de conferir solidez, coerência ou aceitabilidade à doutrina dos direitos dos animais (p. 165).

A literatura sobre o combate ao especismo e em defesa dos animais é bastante extensa. Diversas conquistas foram realizadas, especialmente no que diz respeito ao uso da violência e em defesa do bem-estar animal. Mas os direitos ambientais vão além da condenação ao especismo. Em geral, a legislação reconhece apenas o direito à propriedade de uma natureza que é, essencialmente, fonte de riqueza e de fornecimento de insumos de sobrevivência.

Todavia, em março de 2017, os direitos da natureza, como estabelece os princípios ecocêntricos, foram reconhecidos pelo Parlamento da Nova Zelândia que aprovou o "Te Awa Tupua Bill", dando direitos ao rio Whanganui, tornando-o o primeiro rio do mundo a receber essa designação especial. $\mathrm{O}$ rio Whanganui fica em uma Ilha mais ao norte da Nova Zelândia e é o terceiro maior curso d'água do país, sendo também uma entidade cultural e espiritualmente importante para as tribos nativas da região.

A lei afirma que o rio é "um todo indivisível e vivo" e o rio Whanganui recebeu a capacidade de defender seus direitos através de representantes humanos, um nomeado pelo Whanganui Iwi (povo Maori) e outro pela Coroa (governo da Nova Zelândia). Segundo Chow (2017, online), o ministro das Negociações de Tratamento da Nova Zelândia, Chris Finlayson, disse: "Eu sei que algumas pessoas vão dizer que é muito estranho dar a um recurso natural uma personalidade jurídica, mas não é mais estranho do que as organizações familiares, empresas ou sociedades anônimas".

Sem dúvida a encíclica Laudato $\mathrm{Si}$ ' ajudou no reconhecimento da crise ambiental, contribuiu para a legitimação do Acordo de Paris e para o combate ao processo de degradação dos ecossistemas (ALVES, 2015). Contudo, os desafios são enormes e, diante da manutenção do modelo hegemônico de produção e consumo, 
fica cada vez mais difícil efetivar, conjuntamente, os direitos humanos e os direitos ambientais.

\section{Considerações finais}

Os direitos humanos entraram definitivamente na agenda internacional depois da Declaração dos Direitos do Homem e do Cidadão, de 1789 e se consolidaram após a Declaração Universal dos Direitos Humanos, de 1948. Mas a própria concepção de direitos humanos evoluiu com o tempo e se tornou mais abrangente na medida que novos direitos foram sendo agregados, como os direitos sexuais e reprodutivos, direitos culturais, direitos difusos, etc. Já os direitos ambientais destinados à proteção do meio ambiente ainda estão em processo de consolidação e, por enquanto, são poucos os casos de instrumentos jurídicos, com perspectiva ecocêntrica, que garantem os direitos dos animais e da natureza.

O desafio que está posto no século XXI é atender às necessidades da humanidade, sem comprometer de modo irreversível a riqueza da biodiversidade e o equilíbrio homeostático do clima do Planeta. Isto significa que a economia não pode crescer infinitamente, mas a população também precisaria se ajustar ao “espaço justo" que garanta uma convivência harmoniosa entre as diversas espécies.

Os direitos humanos e os direitos do meio ambiente sofrem ataques conjuntos e o ano de 2016 bateu todos os recordes de assassinatos de pessoas defendendo suas terras, florestas e rios contra as indústrias extrativas, grilagem e o agronegócio. Relatório da ONG Global Witness (2017) - Defensores da terra mostra que houve 200 assassinatos em 24 países em 2016, número maior do que os 185 de 2015. O Brasil lidera o ranking com 49 assassinatos, seguido Colômbia, com 37, Filipinas, com 28; etc. Talvez os números sejam ainda maiores, levando em conta as dificuldades para se obter informações sobre essas mortes. 
Os conflitos ambientais estão crescendo no mundo e o "ecologismo dos pobres" (MARTINEZ-ALIER, 2007) constitui uma importante reflexão sobre as lutas de resistência das populações locais afetadas pelo crescimento destrutivo das empresas nacionais e multinacionais que não se importam de trocar a sustentabilidade ambiental pelo processo desregrado de acumulação de capital.

É neste contexto que diversas igrejas latino-americanas articulam a opção pelos pobres e a favor da liberdade de ação, como nas atividades do "Grito da Terra". No plano internacional, a iniciativa "Global Catholic Climate Movement" (GCCM), busca articular as famílias católicas, em todo o mundo, para colocar em prática os princípios da encíclica Laudato Si', do Papa Francisco, na busca pela Justiça climática, pela adesão à causa ecológica e pela busca de políticas públicas em defesa dos direitos ambientais, em conjunto com o movimento climático mais amplo. A luta pelo empoderamento dos pobres e pela justiça ambiental deve ser articulada com a defesa da autodeterminação reprodutiva.

Os autores da economia ecológica mostram que é impossível o crescimento ilimitado da população e da economia em um planeta finito. Assim, a análise anterior mostrou que é possível, na sociedade como um todo, mas também no campo da religião, articular os direitos reprodutivos de forma conjunta com os direitos humanos e os direitos da natureza, em uma perspectiva de superação dos condicionantes antropocêntricos do modelo econômico hegemônico e se avançar rumo a uma ética compatível com o prisma ecocêntrico, capaz de fazer uma ligação mais forte entre direitos humanos e direitos ambientais.

\section{REFERÊNCIAS}

ABBASI-SHAVAZI, M. J. et. al. The Fertility Transition in Iran: Revolution and Reproduction. Tehran, Springer, 2009.

AgUinagA, Hélio. Pop Eco Pol: reflexões para uma vida melhor. Rio de Janeiro: 1980.

ALVES, J. E. D. Mitos e realidade da dinâmica populacional, Anais... XII Encontro Nacional de Estudos Populacionais. Caxambu: Abep, 2000. 
ALVES, J. E. D. A polêmica Malthus versus Condorcet reavaliada à luz da transição demográfica. Textos para discussão, n. 4, Rio de Janeiro: IBGE, Escola Nacional de Ciências Estatísticas, 2002.

ALVES, J. E. D.; CORREA, S. Demografia e ideologia: trajetos históricos e os desafios do Cairo + 10. Revista Brasileira de Estudos da População, Rio de Janeiro, v.20, n.2, 2003.

ALVES, J. E. D. Demografia, democracia e direitos humanos. Textos para Discussão, Rio de Janeiro, Escola Nacional de Ciências Estatísticas, IBGE, v.18, 2005.

ALVES, J. E. D. A encíclica Laudato Si’: ecologia integral, gênero e ecologia profunda. Revista Horizonte, Belo Horizonte, v. 13, n. 39, 2015.

ALVES, J. E. D.; MARTINE, G. Population, development and environmental degradation In: ISSBERNER, LR. LÉNA, P. Brazil in the Anthropocene: Conflicts between predatory development and environmental policies. New York: Routledge, p. 41-61, 2017.

AMERICAN MUSEUM OF NATURAL HISTORY. Human Population Through Time, Washington, 2016.

BOBBIO, N. A era dos direitos. Rio de Janeiro: Campus, 1992.

BOFF, L. A Terra sujeito de dignidade e de direitos. Portal Ecodebate, Rio de Janeiro, 2010. Disponível em: <https://www.ecodebate.com.br/2010/04/22/a-terra-sujeito-dedignidade-e-de-direitos-artigo-de-leonardo-boff>. Acesso em: 25 jul. 2017.

BOULDING, K. E. The Economics of the Coming Spaceship Earth. In: H. Jarrett (ed.). Environmental Quality in a Growing Economy. Baltimore: Johns Hopkins Pr., 1966, pp. 3-14.

CADWELL, J. C. Theory of fertility decline. London, Academic Press Inc., 1982.

CARSON, R. Silent Spring. Boston: Houghton Mifflin, 1962.

CAVALCANTI, C. Sustentabilidade: mantra ou escolha moral? Uma abordagem ecológicoeconômica. Estudos Avançados, São Paulo, v. 26, n. 74, p. 35-50, 2012.

CAVENAGHI, S.; ALVES, J.E.D. A equidade de gênero e os direitos sexuais e reprodutivos: implicações para o desenvolvimento sustentável e a erradicação da pobreza. In: MARTINE, George (Ed.) População e sustentabilidade na era das mudanças ambientais globais: contribuições para uma agenda brasileira. Belo Horizonte: ABEP, 2012.

CEBALLOS. G. et. al. Biological annihilation via the ongoing sixth mass extinction signaled by vertebrate population losses and declines. Proceedings of the National Academy of Sciences of the United States of America - PNAS, Washington, v. 114, n. 30, 2017.

CHOW, L.. World's First River Given Legal Status as a Person, Ecowatch, 2017. Disponível em: <http://www.ecowatch.com/new-zealand-whanganui-river2315449092.html >. Acesso em: 5 mai. 2017. 
COALE, A.; HOOVER, E. População e desenvolvimento econômico. Rio de Janeiro: Fundo de Cultura, 1966.

CORREA, S.; ALVES, J. E. D. As metas do desenvolvimento do milênio: grandes limites, oportunidades estreitas? Revista Brasileira de Estudos de População, Rio de Janeiro, v. 22, n. 1, p. 177-189, 2005.

CORREA, S.; ALVES, J. E. D.; JANNUZZI, P. M. Direitos e saude sexual e reprodutiva: marco teórico-conceitual e sistema de indicadores In: CAVENAGHI, S. Indicadores municipais de saúde sexual e reprodutiva. Rio de Janeiro: ABEP, 2006, p. 25-62.

CONSTITUIÇÃO DA REPÚBLICA FEDERATIVA DO BRASIL, 1988. Disponível em: <http://www.planalto.gov.br/ccivil_03/constituicao/constituicaocompilado.htm>. Acesso em: 30 jun. 2017

CONSTITUCIÓN DE LA REPÚBLICA DEL ECUADOR, 2008. Disponível em:<http://www.inocar.mil.ec/web/images/lotaip/2015/literal_a/base_legal/A._Constit ucion_republica_ecuador_20o8constitucion.pdf $>$. Acesso em: 30 jun. 2017

DALY, H. On Economics as a "Life Science”. Journal of Political Economy, Chicago, vol. 76, no. 3, p. 392-406, 1968.

DALY, H. Toward a Steady-state Economy. San Francisco: W.H. Freeman, 1973

DALY, H. Economics for a Full World. Dartmouth, 2014.

DARROCH, J. E. et al. Adding It Up: Investing in Contraception and Maternal and Newborn Health. New York: Guttmacher Institute, 2017.

DOM NEVES, L. M. Entre o Nilo, as pirâmides e a esfinge. Jornal do Brasil, Rio de Janeiro, 31 de agosto de 1994.

EHRLICH, P. The Population Bomb. New York: Ballantine Books, 1968.

GALEANO, E. A natureza não é muda Galeano. Carta Maior, São Paulo, 2008.

Disponível em: <http://www.cartamaior.com.br/?/Editoria/Meio-Ambiente/A-naturezanao-e-muda/3/14112>. Acesso em: 11 jun. 2017.

GEORGESCU-ROEGEN, N. The entropy law and the economic process. Cambridge (EUA): Harvard University Press, 1971.

GLOBAL WITNESS. Defenders of the Earth, 2017. Disponível em:

$<$ https://www.globalwitness.org/en/campaigns/environmental-activists/defendersearth >. Acesso em: 11 jun. 2017.

GLOBAL FOOTPRINT NETWORK, 2017. Disponível em:

<http://www.footprintnetwork.org/>. Acesso em: 03 jun. 2017.

HODGSON, D.; WATKINS, S. C. Feminists and neo-malthusians: past and present alliances. Population and Development Review, New York, v.23, n.3, p.469-523, Sept. 1997. 
KOLBERT, E. A Sexta Extinção: Uma história Não Natural. Rio de Janeiro: Intrínseca, 2015 .

ISSBERNER, L. R.; LÉNA, P. Brazil in the Anthropocene: Conflicts between predatory development and environmental policies. 1 ed. New York: Routledge, 2017.

McCLORY, Robert. Turning Point: The Inside Story of the Papal Birth Control Commission, and how Humanae Vitae Changed the Life of Patty Crowley and the Future of the Church. New York: The Crossroad Publishing Company, 1995

McNICOLL, G. Malthus for the twenty-first century. Population and Development Review, New York, v.24, n.2, p.309 -316, Jun. 1999.

MACIEL, M. Edward Wilson pede devolução de metade da Terra para os animais. Planeta Sustentável, 2014. Disponível em: <http://planetasustentavel.abril. com.br/ambiente>. Acesso em: 11 jun. 2017.

MALTHUS, T. R. Ensaio sobre a população. São Paulo: Abril Cultural, 1983.

MARSHALL, T. H. Cidadania, classe social e status. Rio de Janeiro: Zahar, 1967.

MARTINE, G.; ALVES, J. E. D. Economia, sociedade e meio ambiente no século 21: tripé ou trilema da sustentabilidade? Revista Brasileira de Estudos de População, Rio de Janeiro, n. 32, v. 3, 2015.

MARTINEZ-ALIER, J.; MASJUAN, E.. Neo-Malthusianism in the Early 2oth Century, Universitat Autònoma de Barcelona. International Society for Ecological

Economics, Montréal, 11-15 July, 2004.

MARTÍNEZ-ALIER, J. O ecologismo dos pobres: conflitos ambientais e linguagens de valoração. São Paulo: Contexto, 2007.

MEADOWS, D. et. al. Limites do Crescimento. Um relatório para o Projeto do Clube de Roma sobre o Dilema da Humanidade. São Paulo: Editora Perspectiva, $2^{a}$ ed., 1978.

MILARÉ, E.. Responsabilidade Ética em face do Meio Ambiente. Justitia, São Paulo, v. 58 n. 176, out/dez 1996, p. 109-116.

NATIONAL CATHOLIC REPORTER. Devemos ir além do impasse da "Humanae Vitae". IHU, São Leopoldo, 26 jan. 2015. Disponível em: <http://www.ihu.unisinos.br/539268devemos-ir-alem-do-impasse-humanae-vitae> . Acesso em: 15 de mai. 2017

ODUM, H. Environment, power and society. New York: John Wiley \& Sons, 1971.

OLIVEIRA, F. C. S. Especismo Religioso. Revista Brasileira de Direito Animal, Salvador, Ano 6, v. 8, jan-jun 2011, pp: 161-220.

PAPA PAULO VI. Humanae Vitae. Carta Encíclica de Sua Santidade do Papa Paulo VI sobre a Regulação da Natalidade. Vaticano, 25 jul. 1968. 
PAPA FRANCISCO. Discurso na ONU na Cúpula dos ODS, Nova Iorque, Canção Nova, 2015. Disponível em: <https://noticias.cancaonova.com/especiais /pontificado/francisco/discurso-do-papa-francisco-na-onu>. Acesso em: 11 jun. 2017.

PIERUCCI, A. F.. O desencantamento do mundo: todos os passos de um conceito. São Paulo: Editora 34, 2003.

RAWORTH, K.. Doughnut Economics: seven ways to think like a 21st-century economist. NY: Random House Business Books, 2017.

REGAN, T. Animal Rights, Human Wrongs: An Introduction to Moral Philosophy. USA: Rowman \& Littlefield Publishers, 2003.

RELATÓRIO BRUNDTLAND (1987). Comissão Mundial sobre Meio Ambiente e Desenvolvimento. Nosso futuro comum. $2^{\mathrm{a}}$ ed. Rio de Janeiro: Editora da Fundação Getúlio Vargas, 1991.

ROCKSTROM, J. et. al. A safe operating space for humanity. Nature, London, v. 461, n. 24, p. 472-475, 2009.

SABORIT, I. T. Religiosidade na Revolução Francesa [online]. Rio de Janeiro: Centro Edelstein de Pesquisas Sociais, 2009.

SIMÕES, J. O humanismo como resgate ético à ciência tecnocrática, Entrevista a João Vitor Santos, IHU, São Leopoldo, 03/o8/2015. Disponível em:

<http://www.ihuonline.unisinos.br/index.php?option=com_content\&view=article\&id=6o $33 \&$ secao=469>. Acesso em: 27 mai. 2017.

STEFFEN, W. et. al. Planetary boundaries: guiding human development on a changing planet. Science, Washington, v. 347, n. 6223, jan. 2015.

THOREAU, H. D. Walden, ou, a vida nos bosques. $7^{\mathrm{a}}$ ed. São Paulo: Ground, 2007.

UNEP. Global Material Flows And Resource Productivity: Assessment Report for the UNEP International Resource Panel. Jul, 2016.

UNITED NATIONS. Transforming our world: the 2030 Agenda for Sustainable Development, Resolution adopted by the General Assembly on 25 September 2015. Disponível em: <http://www.un.org/ga/search/view_doc.asp? symbol=A/RES/70/1\&Lang=E > . Acesso em: 25 jun. 2017.

WWF - World Wildlife Fund. Living planet report: species and spaces, people and places. 2016 